\title{
EFFECT OF AN INTRA-UTERINE DEVICE ON CONCEPTION AND OVULATION IN THE RHESUS MONKEY
}

\author{
W. A. KELLY,* J. H. MARSTON $\dagger$ aNd P. EGKSTEIN \\ Department of Anatomy, Medical School, Birmingham 15
}

(Received 5th Fuly 1968)

\begin{abstract}
Summary. Groups of twenty-one IUD and twenty-four control rhesus monkeys were regularly mated with males of proved fertility. None of the IUD females became pregnant, but a total of eighteen pregnancies occurred in fifteen of the control monkeys.

A series of observations on the ovaries of control and IUD monkeys examined at laparotomy and autopsy showed that the presence of an IUD affected neither the occurrence nor the timing of ovulation within the natural menstrual cycle.
\end{abstract}

\section{INTRODUCTION}

An intra-uterine device (IUD) is contraceptive in women and is also generally assumed to be contraceptive in the rhesus monkey. Apart, however, from a preliminary communication (Kelly \& Marston, 1967) and the experiments of Eckstein, Kelly \& Marston (1969) showing that an IUD in the rhesus monkey does not affect the natural periodicity or the duration of menstruation, there have been no studies to establish that an IUD is, in fact, contraceptive in the rhesus monkey, or to show whether the occurrence or the timing of ovulation is disturbed by the presence of an IUD.

This paper is the second in a series of communications dealing with the effect of an IUD on conception in the naturally cyclic rhesus monkey. It reports on attempts (a) to establish that an IUD is contraceptive, and (b) to study the effect of an IUD on the occurrence and timing of ovulation.

\section{Animals}

\section{MATERIALS AND METHODS}

Mature female rhesus monkeys with an established menstrual periodicity were used. Full details of their management and preparation have been described by Eckstein et al. (1969).

Six fully mature males were regularly used in the mating experiments. Four males (Nos. 951, 953, 954 and 955) were 20 or more years old and of proved

* Present address: Department of Anatomy, The University, Bristol BS8 1TD.

$\uparrow$ Present address: Physiological Laboratory, Cambridge CB2 3EG. 
fertility. They were maintained on the Birmingham 'Standard' diet (Eckstein \& Kelly, 1966) which is known to be seriously deficient in animal protein and vitamin $B_{12}$. The other two males (Nos. 1532 and 1589) were younger, recently imported and of unproved fertility. They were fed on the Modified Diet $41 \mathrm{~B}$ (Oxoid Ltd). It was occasionally necessary to use five other males for a total of fourteen matings.

\section{Mating procedure}

As a routine, the females were caged with a male from Day 12 to Day 16 of the menstrual cycle, but some matings were started on Day 10. This procedure was followed during the breeding programme, but in other experiments whenever it was necessary to perform an experimental laparotomy, the female was separated from the male, and not returned to him.

A vaginal lavage was taken from the females on each morning of the mating period. A compatible mating was recorded when spermatozoa and/or seminal coagulum were found in at least one of these lavages.

\section{Detection of pregnancy}

Pregnancy was suspected when a monkey had not shown menstrual bleeding for 6 weeks, or when the sex skin showed the blue tinge which is characteristic of pregnancy. Pregnancy was confirmed by bi-manual palpation of the uterus.

\section{Examination of IUD monkeys during the breeding programme}

After the IUD monkeys had each completed two compatible matings, the uterus was palpated before each subsequent mating. At the conclusion of the breeding programme, laparotomy was carried out on each monkey within 1 month of its last mating.

\section{Examination of ovaries}

At laparotomy, the ovaries were carefully examined, and in most cases they were routinely photographed (Betteridge, Kelly \& Marston, unpublished data). At autopsy, or after ovariosalpingectomy, the ovaries were fixed in aqueous Bouin's solution, serially sectioned at $8 \mu$, stained with haematoxylineosin, and examined microscopically.

The morphological condition of the ovaries was correlated with the results of previous examinations at laparotomy and/or attempts to recover eggs from the genital tract (Marston, Kelly \& Eckstein, 1969).

\section{RESULTS}

Effect of an IUD on conception

During the period from January 1966 to January 1967, groups of control and IUD monkeys were regularly mated. The results of the matings are summarized in Table 1 , which shows that none of the twenty-one IUD monkeys became pregnant.

Twelve of the fifteen control monkeys which conceived, required less than three matings to establish their pregnancy; two monkeys conceived after five 
matings, and one did so after six. All of these animals exhibited the 'placental sign' (Hartman, 1929) at about the time menstruation would have occurred in the absence of pregnancy. One monkey showed an additional bleeding 26 days after the 'placental sign', but, apart from this, bleedings were not observed during pregnancy.

The IUD monkeys (and the control animals which did not conceive) continued to show regular menstrual cycles throughout the breeding programme. There was no indication that they might have conceived and then undergone an early abortion. At least three compatible matings were recorded for each of these monkeys and therefore they had a reasonable opportunity to conceive. Laparotomy established that the IUD monkeys had morphologically normal genital tracts at the conclusion of the breeding experiment.

TABLE 1

EFFECT OF AN IUD ON GONCEPTION IN THE RHESUS MONKEY

\begin{tabular}{l|c|c|c|c|c}
\hline & \multicolumn{2}{|c|}{ Females } & \multicolumn{2}{c|}{ Matings } & \multirow{2}{*}{ Conceptions } \\
\cline { 2 - 6 } & Total & Conceiving & Total & Compatible* & \\
\hline Control & 24 & 15 & 75 & 67 & $18 \dagger$ \\
IUD & 21 & - & 92 & 77 & - \\
\hline
\end{tabular}

* Compatible matings established by detection of vaginal spermatozoa.

$\dagger$ Three monkeys each conceived twice.

TABLE 2

FERTILITY OF MALES WHEN MATED WTTH THE FIFTEEN FEMALES THAT CONGEIVED DURING THE BREEDING PROGRAMME

\begin{tabular}{l|r|r|r|r|r|r|r}
\hline & \multicolumn{8}{|c}{ Identification no. of male } \\
\cline { 2 - 8 } & 951 & 953 & 954 & 955 & $1532^{*}$ & $1589 *$ & Others* \\
\hline $\begin{array}{l}\text { Total compatible matings } \\
\text { Conceptions }\end{array}$ & 10 & 9 & 8 & 3 & 2 & 5 & 3 \\
\hline
\end{tabular}

* On animal protein (+ vitamin $B_{12}$ ) diet.

Table 2 shows that there was little difference in the fertility of the males that were regularly used for mating. They all sired at least one pregnancy and there was no evidence that males on a deficient diet were less fertile than those on a complete diet.

Inspection of the mating records showed that the control and IUD females were allowed equal access to the males. There was no difference in the times at which matings were allowed. There was no underlying seasonal variation in the records of compatible matings and conception. Conception was related to the time when the fertile control monkeys were first allowed to mate and not to the season of the year. 
Outcome of pregnancy in the control monkeys

Four of the eighteen pregnancies aborted within 3 months of conception and twelve proceeded to term with the birth of ten living and two dead infants. Two pregnant animals were used in other experiments.

\section{Effect of an IUD on ovulation}

Table 3 summarizes the observations on the ovarian condition of monkeys that were examined at laparotomy or autopsy between Days 11 and 18 of their natural menstrual cycle. There was no significant difference between the results from control and IUD monkeys, and so an IUD did not affect the occurrence of ovulation during the natural menstrual cycle.

\section{Table 3}

$$
\begin{gathered}
\text { effect of an iud on ovulation in rhesus monkeys (monkeys } \\
\text { examined at laparotomy or autopsy) }
\end{gathered}
$$

$\begin{array}{lccccc} & \begin{array}{c}\text { Total no. } \\ \text { monkeys } \\ \text { examined }\end{array} & \begin{array}{c}\text { Total no. } \\ \text { observations }\end{array} & \text { With ovulation } & \text { Pre-ovulatory* } & \text { Inactive }^{\wedge} \\ \text { Control } & 55 & 102 & 73 & 16 & 13 \\ \text { IUD } & 37 & 97 & 68 & 20 & 9 \\ & & & & & \\ & \text { * Observed before Day 16 of menstrual cycle. } \\ \text { t Observed later than Day 13 of menstrual cycle. }\end{array}$

\section{Development of the corpus luteum}

Serial-sections of the ovaries from a series of thirty control and thirty-six IUD monkeys were examined in this study and their corpora lutea were assessed using the histological criteria described by Corner (1945). The corpora lutea were assigned a morphological age, which was checked against the available independent indicators of luteal age. Three corpora lutea were recovered $24 \mathrm{hr}$ after laparotomy had shown that the ovary was in a pre-ovulatory condition. Another twenty-five corpora lutea were recovered at 1 to 4 days after the ovary had shown a recent ovulation spot. In these cases a 'youngest possible age' could be assigned to each corpus luteum. The recovery of eggs from the Fallopian tube and uterus also provided another means of estimating the luteal age.

It was found that the development of the corpus luteum during the first 6 or 7 days after ovulation agreed with the classical description of Corner (1945). There was no difference in the appearance or the development of corpora lutea of similar age recovered from control and IUD monkeys.

\section{Time of ovulation}

It was possible to correlate the time of ovulation within the menstrual cycle in a series of forty-two observations from control monkeys and forty-two from IUD animals. These estimates were based (a) upon the morphological age of the corpus luteum, or (b) the results of repeated examinations at laparotomy, or (c) an estimate based upon the site of recovery and appearance of a naturally 
ovulated egg. The results are presented in Table 4 which shows that the timing of ovulation was practically identical in control and IUD monkeys, and agreed with the observations of Hartman (1944).

Inspection of the data showed that there was no seasonal variation in the occurrence of ovulation and in the observation of inactive ovaries in control and IUD monkeys.

TABLE 4

EFFECT OF AN IUD ON THE TIME OF OVULATION IN RHESUS MONKEYS

\begin{tabular}{|c|c|c|c|c|c|c|c|c|c|}
\hline & \multirow{2}{*}{$\begin{array}{c}\text { Total no. } \\
\text { observations }\end{array}$} & \multicolumn{8}{|c|}{$\begin{array}{c}\text { Day of menstrual cycle on which ovulation probably } \\
\text { occurred* }\end{array}$} \\
\hline & & 9 & 10 & 11 & 12 & 13 & 14 & 15 & 16 \\
\hline $\begin{array}{l}\text { Control } \\
\text { IUD }\end{array}$ & $\begin{array}{l}42 \\
42\end{array}$ & $\begin{array}{l}1 \\
1\end{array}$ & $\begin{array}{l}5 \\
5\end{array}$ & $\begin{array}{l}5 \\
6\end{array}$ & $\begin{array}{l}11 \\
10\end{array}$ & $\begin{array}{l}9 \\
8\end{array}$ & $\begin{array}{l}8 \\
9\end{array}$ & $\begin{array}{l}2 \\
2\end{array}$ & $\begin{array}{l}1 \\
1\end{array}$ \\
\hline
\end{tabular}

* Ovulation time was estimated from youngest possible age of corpus luteum and/or egg.

\section{DISCUSSION}

At present, apart from direct examination of the uterus, there is no means of detecting pregnancy within the first 7 days after implantation in the rhesus monkey. Pregnancy can be detected at later times than these (Tullner \& Hertz, 1966) but it was not practicable to use these techniques in the present experiment. As a result it has been necessary to use considerable care in interpreting the results of the breeding experiment. The 'menstrual bleedings' which were regularly observed in the IUD and infertile control monkeys could also have been (a) 'placental signs' of conceptions that were later resorbed or aborted; or (b) the debris from an early abortion.

It is clear that none of the IUD monkeys became obviously pregnant while they were being mated with males of proved fertility. The results of other experiments show that an IUD causes premature elimination of eggs from the uterus in naturally cyclic rhesus monkeys (Kelly \& Marston, 1967; Marston et al., 1969). It is, therefore, possible to conclude that an intra-uterine device exerts a contraceptive effect in naturally cyclic rhesus monkeys.

The presence of an intra-uterine device did not affect the occurrence or the timing of ovulation within the natural menstrual cycle. The development of the corpus luteum was also completely similar in control and IUD monkeys, and the two groups appeared to be part of the same homogeneous population. It was concluded that an IUD did not exert any obvious effect on ovarian function in the naturally cyclic rhesus monkey. The possibility that there may still be some undetected differences between the endocrine function of the ovaries in control and IUD monkeys cannot be eliminated.

\section{ACKNOWLEDGMENTS}

This work was supported by a grant from the Ford Foundation, New York, whose help we gratefully acknowledge. 
The histological techniques were expertly performed by Miss Margaret Giles, who, with $\mathrm{Mr}$ J. Browning, has given us constant assistance. Mr H. Smith, Mr F. James and Mr G. Tonks were responsible for the care and supervision of the rhesus monkeys.

\section{REFERENCES}

Corner, G. W. (1945) Development, organisation and breakdown of the corpus luteum in the rhesus monkey. Contr. Embryol. 31, 117.

Eckstein, P. \& Kelly, W. A. (1966) A survey of the breeding performance of rhesus monkeys in the laboratory. Symp. zool. Soc. Lond. 17, 91 .

Eckstein, P., Kelly, W. A. \& Marston, J. H. (1969) Effect of an intra-uterine device on menstrual periodicity in the rhesus monkey. F. Reprod. Fert. 19, 133.

Hartman, G. G. (1929) Uterine bleeding as an early sign of pregnancy in the monkey (Macacus rhesus) together with observations on the fertile period of the menstrual cycle. Bull. Johns Hopkins Hosp. 44, 155.

Hartana, G. G. (1944) Recovery of primate eggs and embryos: methods and data on the time of ovulation. West. 7. Surg. Obstet. Gynec. 52, 3.

Kelly, W. A. \& Marston, J. H. (1967) Action of intra-uterine devices in rhesus monkeys. Nature, Lond. 214, 735.

Marston, J. H., Kelly, W. A. \& Eckstein, P. (1969) Effect of an intra-uterine device on gamete transport and fertilization in the rhesus monkey. F. Reprod. Fert. 19, 149.

Tuld.Ner, W. W. \& Hertz, R. (1966) Chorionic gonadotrophin level in the rhesus monkey during early pregnancy. Endocrinology, 78, 204. 